\title{
Swelling Pressure of Double-Expansive Material and Its Active Support Effect for Coal Seam Gas Drainage Borehole
}

\author{
Zhiming Wang ${ }^{1}$ and Yuning Sun $\mathbb{D}^{1,2}$ \\ ${ }^{1}$ School of Energy Science and Engineering, Henan Polytechnic University, Jiaozuo 454002, China \\ ${ }^{2}$ State and Local Joint Engineering Laboratory for Gas Drainage and Ground Control of Deep Mines, \\ Henan Polytechnic University, Jiaozuo 454000, China \\ Correspondence should be addressed to Yuning Sun; sunyn639@126.com
}

Received 13 April 2018; Revised 24 June 2018; Accepted 15 July 2018; Published 2 August 2018

Academic Editor: Shazim A. Memon

Copyright (C) 2018 Zhiming Wang and Yuning Sun. This is an open access article distributed under the Creative Commons Attribution License, which permits unrestricted use, distribution, and reproduction in any medium, provided the original work is properly cited.

\begin{abstract}
To improve coal seam gas drainage performance, we developed a double-expansive (DE) material to seal the borehole. The swelling process of this material includes an initial swelling stage and a secondary swelling stage. We studied the swelling pressure properties of the DE material under four constraint conditions using a self-made swelling test device. Further, the active support effect of the DE material on the borehole was analyzed by simulating borehole stability with COMSOL Multiphysics software. The results exhibit the following: (1) The swelling pressure of the DE material exhibits time-dependent behavior, and the mathematical relationship between the swelling pressure and time can be obtained by nonlinear fitting. (2) The radial swelling potential is principally formed during the secondary swelling stage, providing the main active support on the radial constraint. (3) The active support imposed on the hole wall can prevent the extension of plastic and damage regions around the borehole, for improved stability of the gas drainage borehole. Finally, field tests demonstrate improved gas drainage performance of the borehole sealed by the DE material compared to a conventional sealing material.
\end{abstract}

\section{Introduction}

Coalbed methane $(\mathrm{CBM})$ is an unconventional natural gas and presents hazards in coal mines [1-3]. Methane produces a greenhouse effect that is more than 20 times higher than that of carbon dioxide $[4,5]$. Thus, the development of CBM would benefit coal mine hazard prevention, resource utilization, and environmental protection. Gas drainage via boreholes in the coal seam is the major strategy used to exploit CBM in underground coal mines in China [6-9]. Borehole sealing plays a critical role during the gas drainage process, and the quality of this sealing directly influences gas drainage performance. If the borehole is poorly sealed, the air in the tunnels of coal mines can be inhaled into the gas drainage borehole via fractures, which is considered to be an air leakage phenomenon of gas drainage borehole. This will cause a significant decrease in the concentration of the methane in the drainage borehole [10-12]. When the concentration of methane drops to $5 \%-16 \%$, there are hazards of fire and blasting in the drainage pipe net. Additionally, methane can only be utilized directly when its concentration is above $30 \%$, and it is expensive for current technology to utilize methane that has been diluted to a lower concentration [13].

To reduce the air leakage of gas drainage borehole, efficient sealing materials have been developed. Zhou et al. $[6,14,15]$ developed a secondary hole sealing technology, which is implemented by the introduction of fine expansive particles into seam fractures. The fractures are subsequently blocked by the particles after several days, presenting a barrier to air entering the seam. Zhai and Xiang et al. $[11,16]$ proposed a flexible gel (FG) sealing material with good compactness and stability and utilized an active sealing method to inject the FG material into the fractures around the borehole. Liu et al. [17] tested the shrinkage rate and uniaxial compression strength of a sealing material 
composed of ordinary Portland cement (OPC) and an expansion agent and found that the best material had a water-cement ratio of $0.8: 1$.

Generally, sealing materials with good swelling properties are required to guarantee the sealing quality and to reduce air leakage of drainage boreholes. The swelling pressure of the material can provide active support that acts on the wall of the borehole, to resist borehole deformation, inhibit the development of fractures around the borehole, and reduce air leakage [18]. However, materials that have been applied commercially to seal gas drainage boreholes provide little active support to the hole wall. Therefore, a novel material must be developed that can be used to provide active support on the inner wall of a gas drainage borehole.

The swelling pressure of a material is a resistance to maintain its initial volume and shape [19]. Many researchers have studied the swelling pressure of soil and rock materials, proposing models to predict the swelling pressure and swelling potential based on swelling pressure tests [20-22]. However, the swelling pressure properties of sealing materials throughout the hydration process have rarely been examined in detail. In this study, we developed a DE material to seal gas drainage boreholes. We then used a self-designed swelling test device to analyze the swelling pressure properties of the DE material under four different constraint conditions. Then, adopting COMSOL software, the active support effect of the DE material on the gas drainage borehole was simulated. Finally, field tests were conducted to compare the gas drainage performances of boreholes sealed by the DE material and conventional sealing material. Our results provide insight into how to accurately assess the swelling pressure of the sealing material during hydration and thus will serve as a reference for the future study of efficient sealing materials for coal seam gas drainage.

\section{Materials and Methods}

\subsection{DE Material}

2.1.1. Composition of the DE Material. The DE material is composed of main raw material and supplementary material, combined at a mass ratio of $17: 3$. The main raw material is composed of OPC and mineral powder (at a mass ratio of $8: 9$ ). The supplementary material includes a solid expansion agent, bentonite, naphthalene water reducer, and aluminum powder (mass ratio of $26: 6: 1: 1$ ). The chemical composition of the solid expansion agent includes $\mathrm{MgO}(4.1 \%), \mathrm{CaO}$ (26.8\%), $\mathrm{CaSO}_{4}(19.2 \%), \mathrm{SiO}_{2}(31.1 \%)$, and $\mathrm{Al}_{2} \mathrm{O}_{3}(18.3 \%)$, with a loss on ignition of $0.5 \%$. The bentonite that acts as an efficient suspending agent $[23,24]$ can prevent separation of the DE paste during solidification. The naphthalene water reducer acts to reduce water consumption. The optimal water-solid ratio of the DE material is $0.8: 1$. At this optimal water-solid ratio, the $\mathrm{DE}$ material has a compression strength that ranges from $2.9 \mathrm{MPa}$ to $3.6 \mathrm{MPa}$, a fluidity of $213 \mathrm{~mm}$, and a setting time of about 15 hours.

2.1.2. Basic Properties of the DE Material. According to our prior results of applying the free swelling test to the DE material using Le Chatelier's rubber bag method [25], the DE material initially swells rapidly and then continues to swell slowly for a long time (Figure 1). The volume of the DE material at the 168th hour is obviously larger than that at the 16th hour. Therefore, the swelling process can be divided into an initial swelling stage (0-16th hour) and a secondary swelling stage (16th hour-240th hour). In an alkaline solution environment, hydrogen is generated by the chemical reaction between the aluminum powder and water [26], which induces the fast swelling of the DE material during the initial swelling stage. However, this fast swelling attenuates gradually, due to the decrease of the aluminum powder in the material.

The microstructure properties of the DE material were previously characterized by environmental scanning electron microscopy (FEI Quanta 250 FEG-SEM) at a magnification of 3000 times and using an energy dispersion spectrometer (Bruker Quantax 200 Xflash; resolution is superior to $129 \mathrm{eV}$ ). Micrographs of the DE material at the 16th hour and 168th hour after the start of hydration are plotted in Figures 2(a) and 2(b), respectively, and the energy dispersive spectrums of the principal crystals are shown in Figures 2(c) and 2(d). The data showed the formation of ettringite (AFt) and portlandite $(\mathrm{CH})$ crystals in the $\mathrm{DE}$ material during its hydration. The sizes of these two crystals at the 168th hour were both larger than those at the 16th hour. This indicates the AFt and $\mathrm{CH}$ crystals both grow or expand after the solidification of the DE material. The number of the AFt crystal at the 168th hour was more than that at the 16th hour, but there was no obvious variation for the $\mathrm{CH}$ crystals.

\subsection{Swelling Pressure Test Method}

2.2.1. Swelling Test Device and Theory. A swelling test device was designed to measure the swelling pressure of the DE material (Figure 3). This device is made up of a hollow cylinder with an inner diameter of $50 \mathrm{~mm}$ and height of $100 \mathrm{~mm}$, four bolts with $7 \mathrm{~mm}$ diameter, an upper plate with $30 \mathrm{~mm}$ thick, and a base that is $30 \mathrm{~mm}$ thick. Three strain gauges, whose axes are perpendicular to the axis of the cylinder, are pasted on the outer wall of the cylinder. The hoop strain $\left(d_{\mathrm{tw}}\right)$ at the outer wall of the cylinder can be measured by the strain gauges. And there is a stress gauge set in the base. The stress gauge and the strain gauges are connected to data acquisition devices 1 and 2, respectively. USB cables allow transmittance of the experimental data to a computer from the data acquisition devices.

The swelling pressure of the DE material during its hydration can be divided as the radial swelling pressure $\left(P_{\mathrm{r}}\right)$ and the axial swelling pressure $\left(P_{\mathrm{a}}\right)$, along the radial and axial directions of the cylinder, respectively. $P_{\mathrm{a}}$ can be monitored directly by the stress gauge set in the base. Using the swelling test device, $P_{\mathrm{r}}$ cannot be measured directly but can be calculated by $d_{t w}$. Due to the radial deformation of the hollow cylinder that is only induced by $P_{\mathrm{r}}$ (as an internal pressure in the cylinder), the analytical solution of the hoop strain $\left(d_{t}\right)$ in the cylinder wall is expressed as follows [27]: 


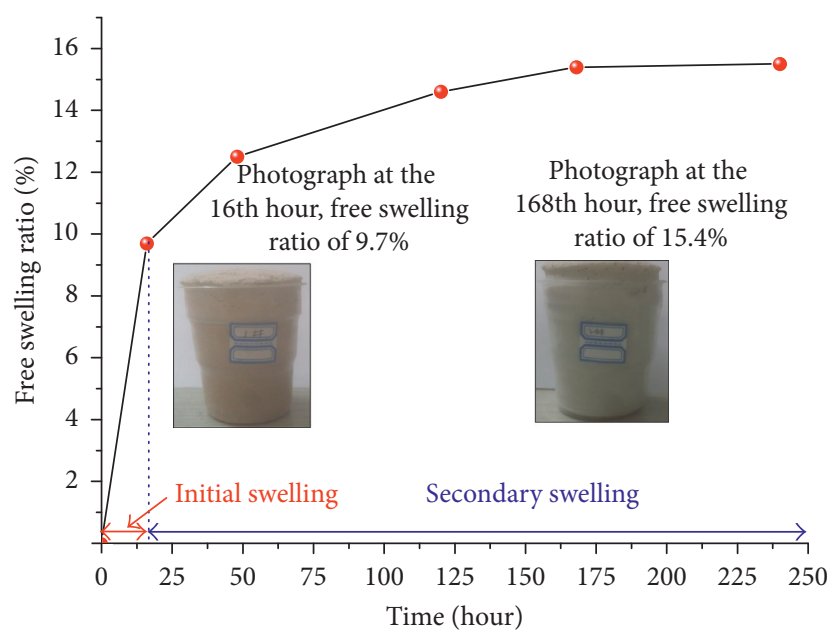

FIGURE 1: Free swelling ratio of the DE material during hydration with macrographs of the material at the 16th hour and the 168th hour.

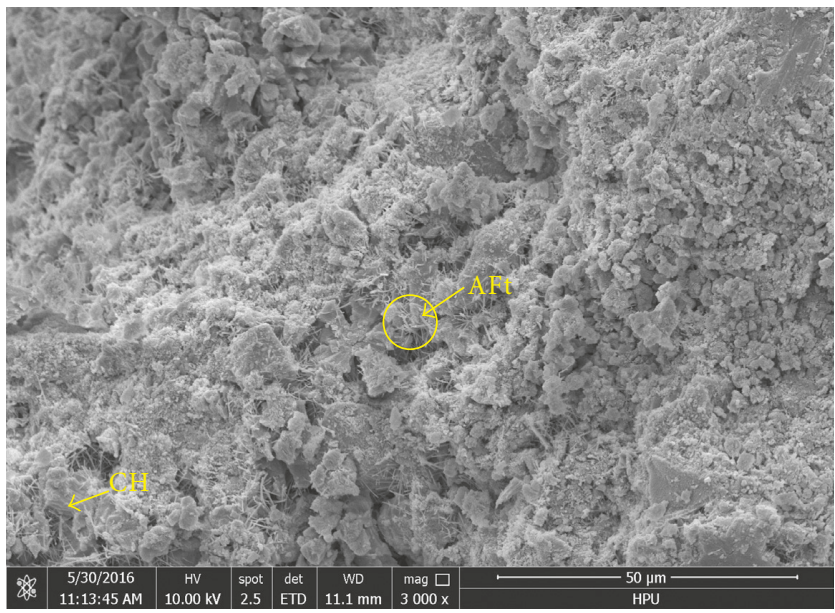

(a)

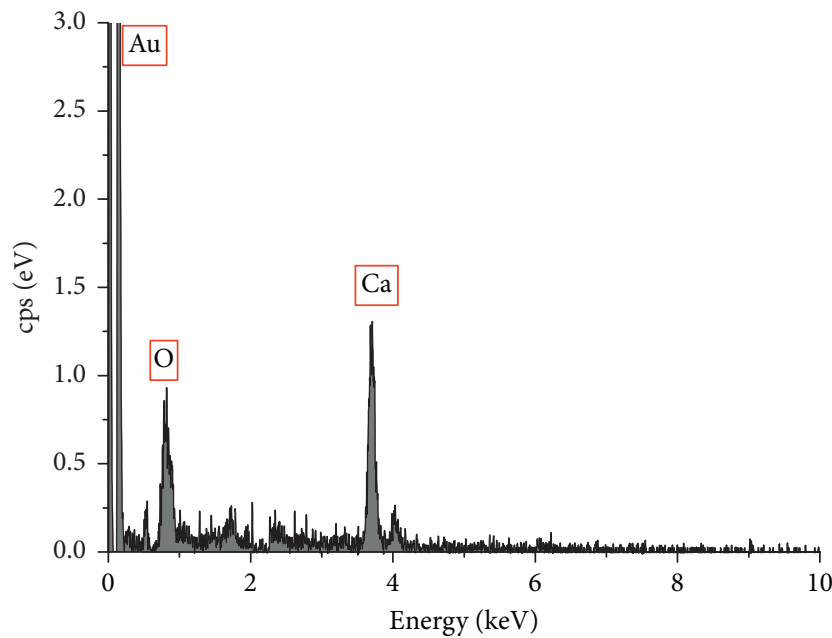

(c)

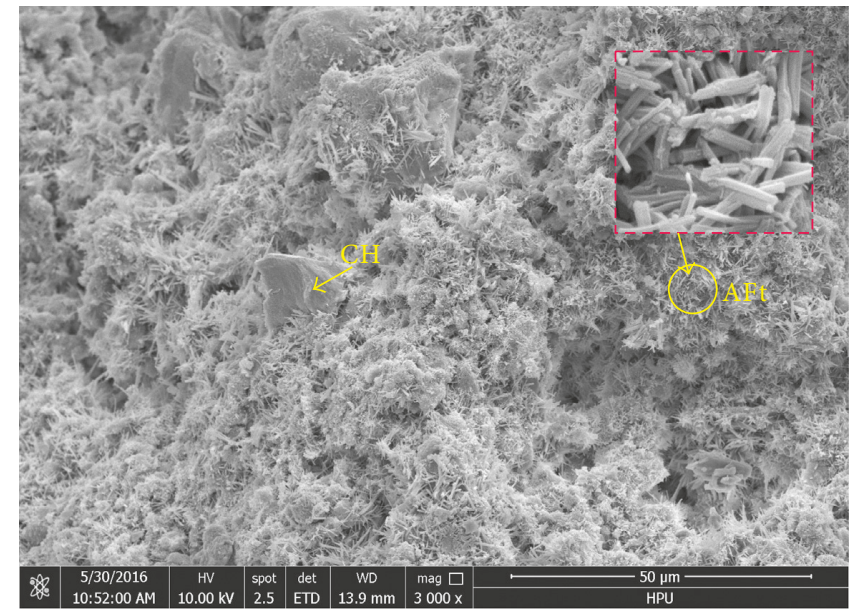

(b)

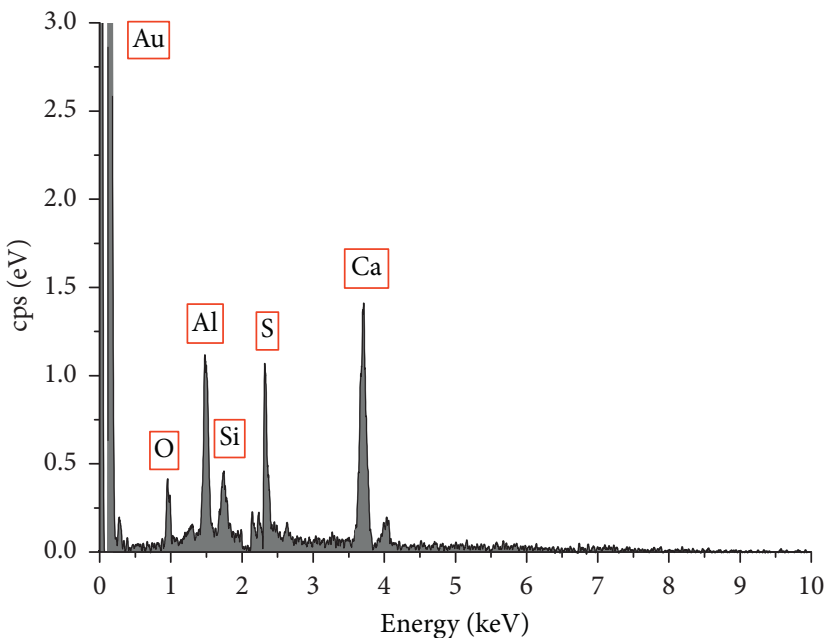

(d)

Figure 2: The micrographs of the DE material and the EDS of the $\mathrm{CH}$ and Aft crystals: (a) micrograph at the 16th hour; (b) micrograph at the 168th hour; (c) EDS of CH crystal; (d) EDS of AFt crystal. 


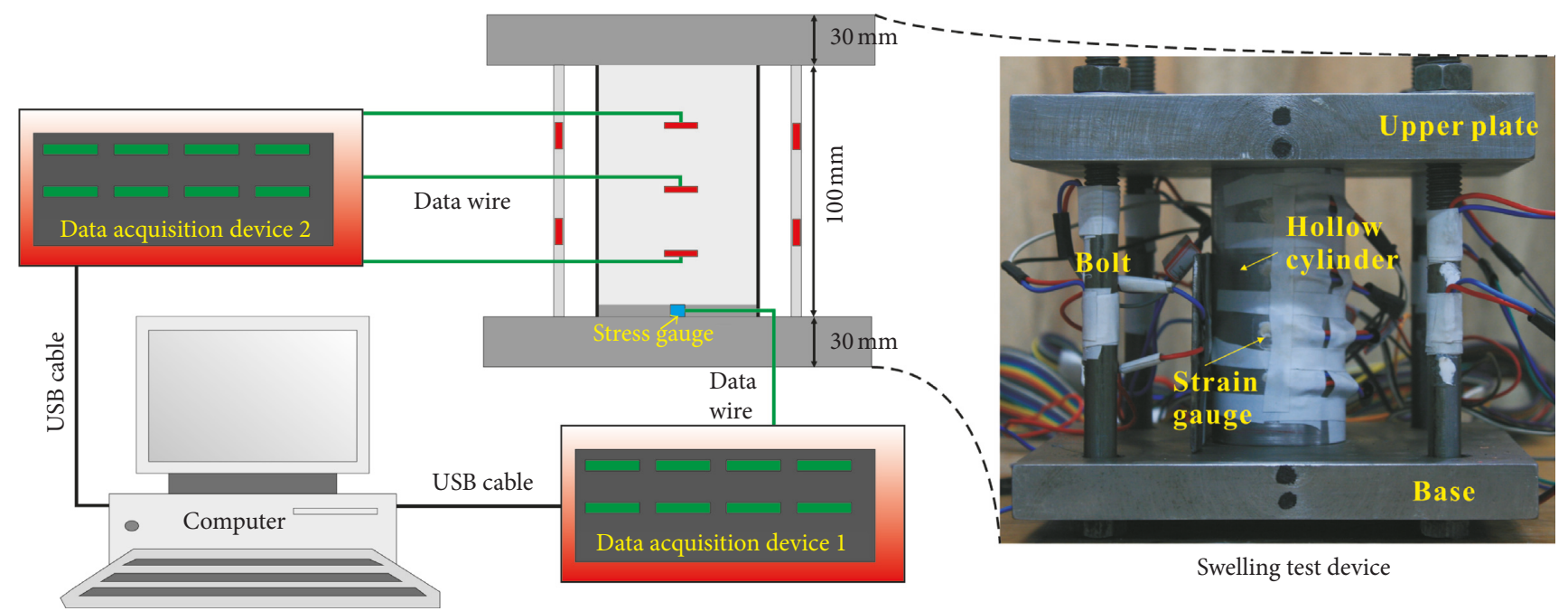

FIgURE 3: Swelling test device and the connections with the computer and data acquisition devices.

$$
d_{t}=\frac{1+\mu}{E} \frac{P_{\mathrm{r}} \cdot r_{\mathrm{c}}^{2}}{\left(r_{0}+\delta\right)^{2}-r_{\mathrm{c}}^{2}}\left(1-2 \mu+\frac{\left(r_{0}+\delta\right)^{2}}{r^{2}}\right)
$$

where $E$ and $\mu$ are Young's modulus and the Poisson ratio of the cylinder material, respectively, $r_{c}$ is the elastic-plastic critical radius in the cylinder, $r_{0}$ is the inner radius of the cylinder, $\delta$ is the thickness of the cylinder, $r_{0}+\delta$ is the initial outer radius of the cylinder, and $r$ is the distance to the axis of the cylinder.

The swelling pressure of the DE material is far less than the yield strength of the cylinder material $(355 \mathrm{MPa})$. Therefore, the entire cylinder remains elastic, and we can obtain

$$
r_{\mathrm{c}}=r_{0} \text {. }
$$

Incorporating (2) into (1), the hoop strain of the cylinder can be rewritten as

$$
d_{t}=\frac{1+\mu}{E} \frac{P_{\mathrm{r}} \cdot r_{0}^{2}}{\left(r_{0}+\delta\right)^{2}-r_{0}^{2}}\left(1-2 \mu+\frac{\left(r_{0}+\delta\right)^{2}}{r^{2}}\right) .
$$

Then, $d_{\mathrm{tw}}$ can be expressed as

$$
d_{\mathrm{tw}}=\left.d_{t}\right|_{r=r_{0}+\delta}=\frac{1+\mu}{E} \frac{2 P_{\mathrm{r}} \cdot r_{0}^{2}}{\left(r_{0}+\delta\right)^{2}-r_{0}^{2}}(1-\mu) .
$$

Therefore, $P_{\mathrm{r}}$ can be derived as

$$
P_{\mathrm{r}}=\frac{E\left(\left(r_{0}+\delta\right)^{2}-r_{0}^{2}\right) \cdot d_{t w}}{2\left(1-\mu^{2}\right) r_{0}^{2}} .
$$

2.2.2. Test Procedure. Using the swelling test device, the swelling pressure test procedure can be summarized as follows:

(i) Test device connection: The swelling test device, data acquisition devices, and computer were connected according to Figure 3. The upper plate was not installed at this step. (ii) DE paste preparation: According to GB/T 13462011, 500 grams of the DE material and 400 grams of water were stirred twice in a slurry agitator, at $25^{\circ} \mathrm{C}$. The first stirring is performed at a rate of $140 \mathrm{r} / \mathrm{min}$ for $120 \mathrm{~s}$. Then, stirring is stopped for $15 \mathrm{~s}$. Finally, the second stirring is performed at a rate of $285 \mathrm{r} / \mathrm{min}$ for $120 \mathrm{~s}$.

(iii) Monitoring of swelling parameters and data processing: After DE paste sample preparation, the paste sample was immediately transported into the hollow cylinder. When the cylinder was full, the upper plate was installed on the cylinder and fixed by bolts and nuts (Figure 3). Then, the swelling parameters of $P_{\mathrm{a}}$ and $d_{\mathrm{tw}}$ were monitored by the computer via the data acquisition devices for 240 hours. Finally, using (5), $P_{\mathrm{r}}$ could be calculated using $d_{\mathrm{tw}}$.

2.2.3. Test Scheme. With swelling, the DE material was constrained radially by the hollow cylinder and constrained axially by the bolts. We aimed to investigate the swelling pressures of the DE material in four hollow cylinders of different dimensions and different radial constraint stiffness $\left(S_{\mathrm{r}}\right)$. However, the axial constraint stiffness $\left(S_{\mathrm{a}}\right)$ of the bolts was maintained constant at $126.8 \mathrm{MPa} \cdot \mathrm{m}^{2}$. Table 1 lists the constraint stiffness used in the four tests.

\section{Results and Discussion}

3.1. Time-Dependent Behavior of Swelling Pressure. The swelling pressure of the DE material exhibited a significant time-dependent characteristic during its hydration, as shown in Figure 4. The swelling pressures, including $P_{\mathrm{r}}$ and $P_{\mathrm{a}}$, increased over time initially and then tended to be stable gradually. For instance, in test no. $1\left(S_{\mathrm{r}}=41.2 \mathrm{MPa} \cdot \mathrm{m}^{2}\right.$ and $\left.S_{\mathrm{a}}=126.8 \mathrm{MPa} \cdot \mathrm{m}^{2}\right), P_{\mathrm{r}}$ and $P_{\mathrm{a}}$ are $0.63 \mathrm{MPa}$ and $0.49 \mathrm{MPa}$ at 34 hours after the starting hydration of the DE material (Figure $4(\mathrm{a})$ ). Then, $P_{\mathrm{r}}$ and $P_{\mathrm{a}}$ rapidly increased between the 
TABLE 1: Constraint stiffness in the four tests.

\begin{tabular}{lcccc}
\hline Test no. & $\delta(\mathrm{mm})$ & $r_{\mathrm{b}}{ }^{*}(\mathrm{~mm})$ & $S_{\mathrm{r}}\left(\mathrm{MPa} \cdot \mathrm{m}^{2}\right)$ & $S_{\mathrm{a}}\left(\mathrm{MPa} \cdot \mathrm{m}^{2}\right)$ \\
\hline 1 & 2 & 7 & 41.2 & 126.8 \\
2 & 3 & 7 & 61.8 & 126.8 \\
3 & 4 & 7 & 82.4 & 126.8 \\
4 & 5 & 7 & 103 & 126.8 \\
\hline
\end{tabular}

${ }^{*}$ Radius of the bolt.

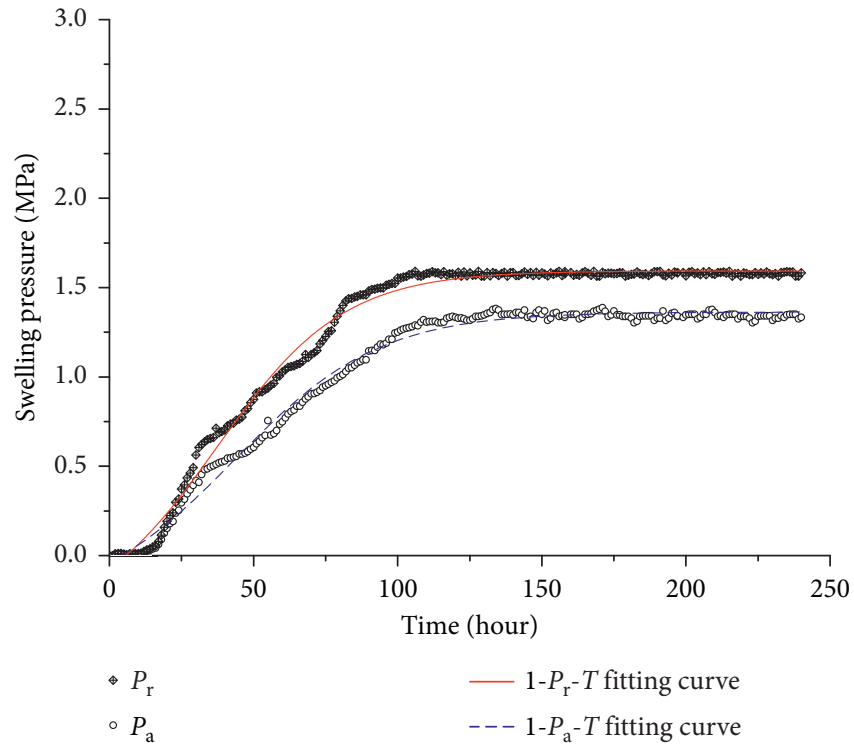

(a)

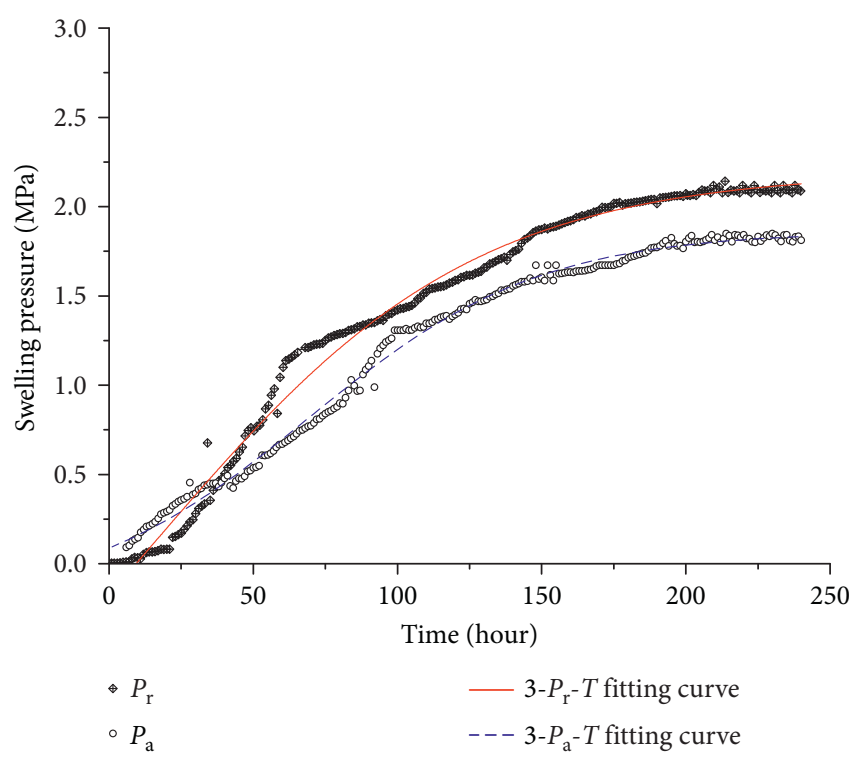

(c)

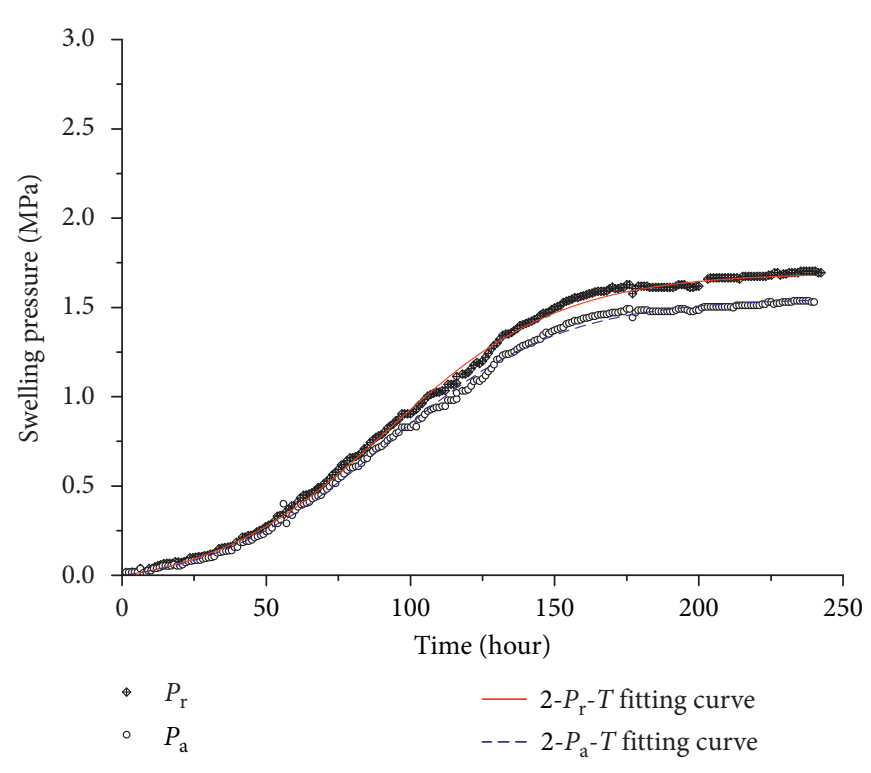

(b)

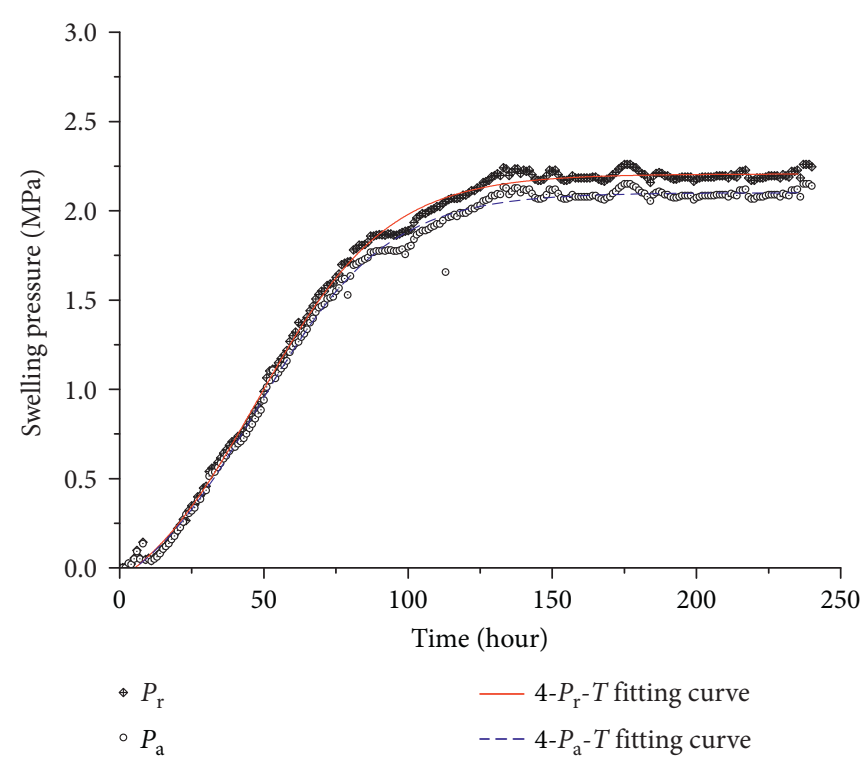

(d)

FIGURE 4: Variations of swelling pressure over time: (a) radial and axial swelling pressures-time curves in test no. 1; (b) radial and axial swelling pressures-time curves in test no. 2; (c) radial and axial swelling pressures-time curves in test no. 3; (d) radial and axial swelling pressures-time curves in test no. 4 .

34th hour and the 83rd hour. Finally, $P_{\mathrm{r}}$ and $P_{\mathrm{a}}$ increased slowly and reached the stable values of $1.58 \mathrm{MPa}$ and 1.37 $\mathrm{MPa}$, respectively. The stable value is the maximum swelling pressure (MSP). For the other tests, the tendency of the swelling pressure to vary over time is consistent with that in test no. 1. The time-dependent swelling pressure of the DE material agrees with the results of Shi $[28,29]$.

The time $\left(t_{\mathrm{m}}\right)$ to reach the maximum radial swelling pressure (MSP-r) is similar to that of the maximum axial swelling pressure (MSP-a). Specifically, $t_{\mathrm{m}}$ is about 116.5 hours 
in test no. 1, 166 hours in test no. 2, 201 hours in test no. 3, and 131 hours in test no. 4 . However, there is also a difference in the values of $t_{\mathrm{m}}$ for different tests. For $S_{\mathrm{r}}<82.4 \mathrm{MPa} \cdot \mathrm{m}^{2}, t_{\mathrm{m}}$ increased with $S_{\mathrm{r}}$. However, for $S_{\mathrm{r}}=82.4 \mathrm{MPa} \cdot \mathrm{m}^{2}$ in test no. 4 , the value of $t_{\mathrm{m}}$ decreased significantly. As discussed in Section 2.1.2, formation and growth of AFt and $\mathrm{CH}$ occurs in the $\mathrm{DE}$ material after solidification. Furthermore, based on many prior studies [30-35], the continuous formation and growth of AFt is a major contributor to the swelling of many inorganic materials. The chemical reaction of forming AFt is as follows:

$$
\begin{aligned}
6 \mathrm{Ca}^{2+} & +2 \mathrm{Al}(\mathrm{OH})_{4}^{-}+4 \mathrm{OH}^{-}+3 \mathrm{SO}_{4}^{2-}+26 \mathrm{H}_{2} \mathrm{O} \\
\longrightarrow & \mathrm{Ca}_{6}\left[\mathrm{Al}(\mathrm{OH})_{6}\right]_{2} \cdot\left(\mathrm{SO}_{4}\right)_{3} \cdot 26 \mathrm{H}_{2} \mathrm{O}(\mathrm{AFt})
\end{aligned}
$$

From (6), it is clear that the formation and growth process of AFt is influenced by the transmission of ions in the DE material. After the hardening of the DE material, with aluminum, calcium, and sulfate ions present in the pores that continued to concentrate around the AFt, the AFt forms and grows over time [31-33]. A counterforce from the constraint is imposed on the DE material. The counterforce has a positive correlation with the swelling pressure and increases with $S_{\mathrm{r}}$. Pores in the DE material may be partially compressed under the counterforce, which hinders ion migration and prolongs the formation and growth process of AFt. When $S_{\mathrm{r}}$ increases to $82.4 \mathrm{MPa} \cdot \mathrm{m}^{2}$, the swelling pressure becomes much larger. Therefore, the pores in the DE material may be compressed further or be completely under a relatively high counterforce, which may drive some of the ions that are migrating from pores to gather together. The formation and growth progress of AFt will be much shorter. Therefore, the $t_{\mathrm{m}}$ of test no. 4 was less than that of test nos. 2 and 3 . However, the critical counterforce, which reduces $t_{\mathrm{m}}$, was not determined in this study.

The time-dependent behavior of the swelling pressure is shown in Figure 4 and can be applied to evaluate the stability of a coal seam borehole and to estimate air leakage [18]. To mathematically describe the time-dependent behavior of the swelling pressure, (7a) was introduced for nonlinear fitting:

$$
P=A_{2}+\frac{A_{1}-A_{2}}{1+\exp ((t-a) / b)},
$$

where $A_{1}, A_{2}, a$, and $b$ represent the fitting parameters and $t$ is time.

After nonlinear fitting, the fitting parameters are listed in Table 2. The correlation coefficients between the fitting equation and the experimental data are larger than 0.98 . Therefore, (7a) can be used to accurately describe the timedependent behavior of the swelling pressure. Moreover, from the fitting results, it can be seen that the fitting parameter $A_{2}$ roughly coincides with MSP, and the parameter $A_{1}$ is close to 0 . Hence, the time-dependent behavior of the swelling pressure can be described as

$$
P=\operatorname{MSP} \cdot \frac{\exp ((t-a) / b)}{1+\exp ((t-a) / b)} \text {. }
$$

3.2. Radial Swelling Potential at Each Stage. Based on the results of the swelling pressure tests, the radial swelling pressures produced at different swelling stages are plotted in
TABLE 2: Fitting parameters of the fitting curves.

\begin{tabular}{lccccc}
\hline $\begin{array}{l}\text { Fitting } \\
\text { curves }\end{array}$ & $A_{1}$ & $A_{2}$ & $a$ & $b$ & $R^{2}$ \\
\hline $1-P_{\mathrm{r}}-T$ & -0.27 & 1.58 & 41.31 & 21.48 & 0.991 \\
$1-P_{\mathrm{a}}-T$ & 0.03 & 1.37 & 49.43 & 24.39 & 0.990 \\
$2-P_{\mathrm{r}}-T$ & -0.09 & 1.68 & 91.77 & 31.00 & 0.987 \\
$2-P_{\mathrm{a}}-T$ & -0.08 & 1.53 & 91.77 & 31.00 & 0.987 \\
$3-P_{\mathrm{r}}-T$ & -1.42 & 2.15 & 28.67 & 49.57 & 0.986 \\
$3-P_{\mathrm{a}}-T$ & -0.34 & 1.97 & 66.46 & 45.75 & 0.993 \\
$4-P_{\mathrm{r}}-T$ & -0.35 & 2.21 & 47.48 & 22.59 & 0.997 \\
$4-P_{\mathrm{a}}-T$ & -0.33 & 2.09 & 47.48 & 22.59 & 0.997 \\
\hline
\end{tabular}

Figure 5. The radial swelling pressures were less than $0.125 \mathrm{MPa}$ at the initial swelling stage (0-16th hour). However, the radial swelling pressures produced at the secondary swelling stage (17th hour-240th hour) are $1.526 \mathrm{MPa}$, 1.614 MPa, 2.057 MPa, and 2.08 MPa in test nos. 1, 2, 3, and 4, respectively. This result indicates that the radial swelling pressure produced at the secondary swelling stage is larger than that at the initial swelling stage and increases with $S_{\mathrm{r}}$.

In practice, the swelling potential of the DE material energy is released radially and axially, and it is the radial swelling potential that is a key for the active support acting on the gas drainage borehole wall. For the laboratory tests, the radial swelling pressure, as an internal pressure, does work to the hollow cylinder, and then elastic energy $\left(W_{\mathrm{H}}\right)$ is saved in the hollow cylinder. Hence, $W_{\mathrm{H}}$ can be adopted to assess the radial swelling potential of the DE material. In this paper, we define $W_{\mathrm{H}}$ as the radial swelling potential index (RSPI) of the DE material. Based on the elastic theory and by applying the integration method, the $W_{\mathrm{H}}$ and the RSPI can be expressed as follows (Appendix A):

$$
\begin{aligned}
W_{\mathrm{H}} & =\mathrm{RSPI}=\int_{r_{0}}^{r_{0}+\delta} \int_{0}^{2 \pi} \frac{A}{r}\left(B+\frac{C}{r^{2}}\right) d \varphi d r, \\
A & =\frac{P_{\mathrm{r}}^{2} r_{0}^{3} L_{0}(1+\mu)}{2 \delta E}, \\
B & =1-2 \mu, \\
C & =\left(r_{0}+\delta\right)^{2} .
\end{aligned}
$$

The RSPI of the DE material at different swelling stages is illustrated in Figure 6. The values of RSPI at the initial swelling stage were $0.147 \times 10^{-4} \mathrm{~J}, 0.155 \times 10^{-4} \mathrm{~J}, 0.421 \times 10^{-4} \mathrm{~J}$, and $0.724 \times 10^{-4} \mathrm{~J}$ in test nos. $1,2,3$, and 4 , respectively. However, the values of RSPI at the secondary swelling stage were $12.58 \times 10^{-4} \mathrm{~J}, 13.79 \times 10^{-4} \mathrm{~J}, 22.44 \times 10^{-4} \mathrm{~J}$, and $23.29 \times 10^{-4} \mathrm{~J}$ for the four tests, showing that the values of RSPI increase with $S_{\mathrm{r}}$. Furthermore, the values of RSPI at the initial swelling stage were much lower than those at the secondary swelling stage.

In the initial swelling stage, the swelling of the DE material is mainly caused by the foaming effect of the aluminum powder. Then, a porous structure is formed in the DE material, as shown schematically in Figure 7(a), which includes pores, calcium silicate hydrates (C-S-H), AFt crystals, and $\mathrm{CH}$ crystals. The $\mathrm{AFt}$ and $\mathrm{CH}$ crystals formed at 


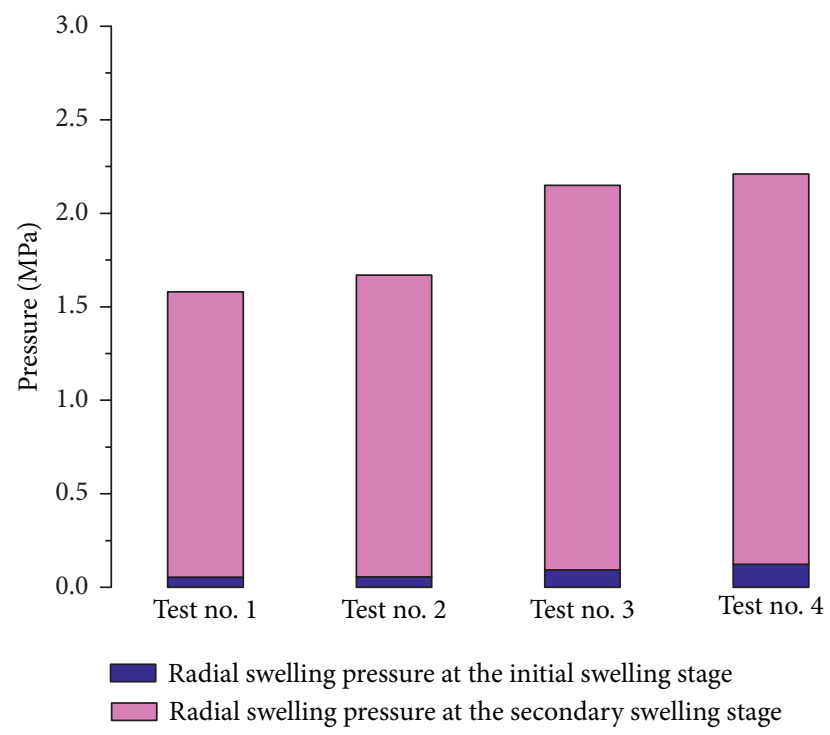

FIgURE 5: Radial swelling pressures produced at different swelling stages.

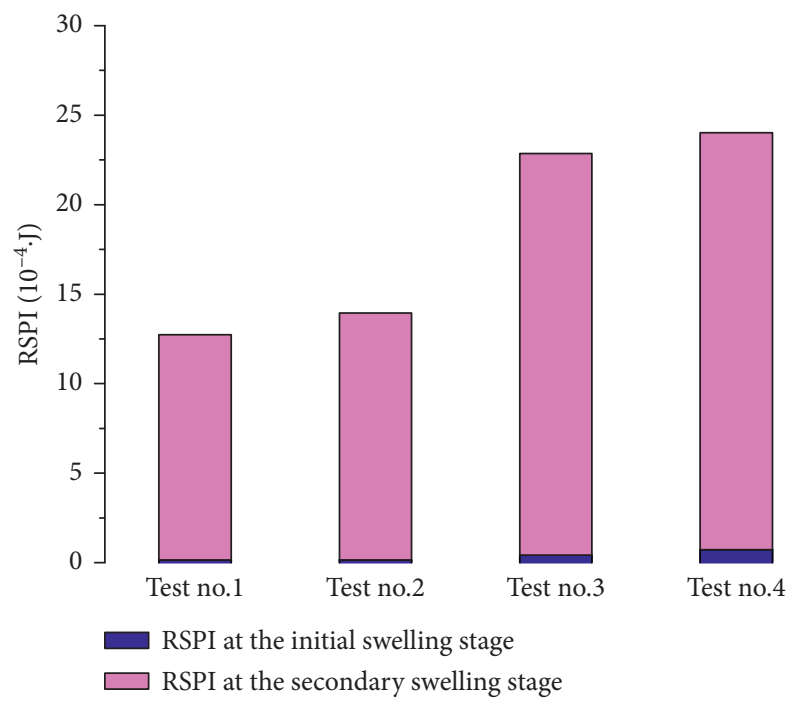

Figure 6: RSPI at different swelling stages.

this stage do not play a role in the swelling of the $\mathrm{DE}$ material, but they do enhance the strength of the material in this initial phase [36]. The swelling potential caused by the foaming effect is very low, and due to the compressibility of the porous structure at this stage, the swelling potential energy can be easily absorbed by the compression of the pores. That is why the value of the RSPI is very low at this stage. However, the fast swelling in this initial swelling stage ensures that the gas drainage borehole is sealed quickly.

In the secondary swelling stage, the DE material has been solidified. The schematic for the morphology model of hydrates of the DE material in the secondary swelling stage is illustrated in Figure 7(b). The pores become smaller than those at the 16th hour, and the AFt and $\mathrm{CH}$ crystals become larger. The swelling is mainly caused by the formation or growth of the crystals, which exert a notable pressure on the surrounding medium [35,37-39]. When there is a slight radial deformation of the hollow cylinder, much elastic energy will be stored in the cylinder. Therefore, the radial swelling potential of the $\mathrm{DE}$ material is mainly formed in the secondary swelling stage, causing main active support on the radial constraint.

\subsection{Active Support Effect of DE Material for a Gas Drainage Borehole}

\subsubsection{Coal Creep Model and Validation}

(1) Creep Model of Coal. Coal is a typical viscoelastic-plastic medium [40]. It is necessary to consider its creep property to study the stability of the borehole. In this study, a creep model consisting of Burgers body (Kelvin body in series with Maxwell body) in series with a plastic element was adopted. The Burgers body reflects the viscoelastic deformation of coal, and the plastic element controls the failure of coal, which is determined by the Mohr-Coulomb yield criterion, F: 


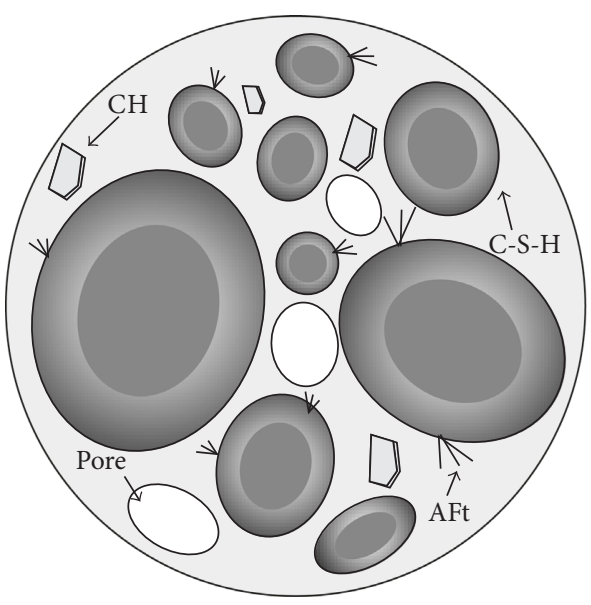

(a)

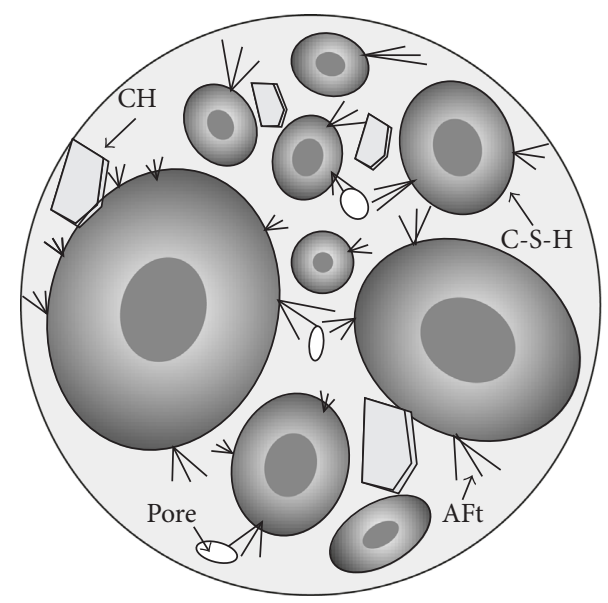

(b)

FIgURE 7: Schematic for the morphology model of hydrates in the DE material: (a) initial swelling stage; (b) secondary swelling stage.

$$
F=\sigma_{1}-\frac{1+\sin \phi}{1-\sin \phi} \sigma_{3}-\sigma_{s}
$$

where $\sigma_{1}$ and $\sigma_{3}$ are the maximum and minimum principal stresses, $\varphi$ is the internal friction angle, and $\sigma_{\mathrm{s}}$ is the uniaxial compressive strength.

For $F<0$, the plastic element does not work. The creep equation of coal in the viscoelastic deformation stage can be expressed as follows [41]:

$$
e_{i j(t)}^{v e}=\frac{S_{i j}}{2 G_{\mathrm{M}}}+\frac{S_{i j}}{2 \eta_{\mathrm{M}}} t+\frac{S_{i j}}{2 G_{\mathrm{K}}}\left(1-e^{-\left(G_{\mathrm{K}} / \eta_{\mathrm{K}}\right) t}\right),
$$

where $e_{i j(t)}^{v e}$ is the deviatoric strain tensor at the viscoelastic deformation stage, $S_{i j}$ is the deviatoric stress tensor, $G$ and $\eta$ are the shear modulus and the viscosity coefficient, respectively, and the subscripts " $M$ " and " $K$ " represent the Maxwell body and Kelvin body in the Burgers body.

Assuming the coal is an isotropic material, the elastic constitutive relation can be expressed as follows:

$$
\begin{aligned}
& S_{i j}=2 G e_{i j}, \\
& \sigma_{\mathrm{m}}=3 K \varepsilon_{\mathrm{m}}, \\
& S_{i j}=\sigma_{i j}-\sigma_{\mathrm{m}} \delta_{i j}, \\
& e_{i j}=\varepsilon_{i j}-\varepsilon_{\mathrm{m}} \delta_{i j},
\end{aligned}
$$

where $K$ is the bulk modulus, $\sigma_{i j}$ and $\varepsilon_{i j}$ are stress and strain tensors, respectively, $\sigma_{\mathrm{m}}=\sigma_{\mathrm{kk}} / 3$ and $\varepsilon_{\mathrm{m}}=\varepsilon_{\mathrm{kk}} / 3$ represent the average normal strain and stress, respectively, and $\delta_{\mathrm{ij}}$ is the Kronecker delta.

Incorporating (11) and (12) into (10), the viscoelastic strain in three dimensions is obtained as

$$
\begin{aligned}
\varepsilon_{i j}^{v e}= & \left(\sigma_{i j}-\sigma_{m} \delta_{i j}\right) \\
& \cdot\left[\frac{1}{2 G_{\mathrm{M}}}+\frac{1}{2 \eta_{\mathrm{M}}} t+\frac{1}{2 G_{\mathrm{K}}}\left(1-e^{-\left(G_{\mathrm{K}} / \eta_{\mathrm{K}}\right) t}\right)\right]+\frac{\sigma_{m}}{3 K} .
\end{aligned}
$$

For $F=0$, based on the nonassociated flow rule, the strain increment of the plastic element can be expressed as follows:

$$
d \varepsilon_{i j}^{p}=d \lambda \frac{\partial Q}{\partial \sigma_{i j}},
$$

where $d \lambda$ is the plastic multiplier and $Q$ is the plastic potential function, which is expressed as follows:

$$
Q=\sigma_{1}-\frac{1+\sin \psi}{1-\sin \psi} \sigma_{3}-\frac{2 c \cos \psi}{1-\sin \psi},
$$

where $c$ is the cohesion of coal and $\psi$ is the dilatation angle.

(2) Model Verification. To verify the proposed creep model, the creep behavior of the coal sample, from the no. 2 coal seam in Huangling no. 2 coal mine, was tested under triaxial stress condition $\left(\sigma_{1}=7 \mathrm{MPa}\right.$ and $\left.\sigma_{2}=\sigma_{3}=3 \mathrm{MPa}\right)$. In accordance with (13) and the experimental data, the creep parameters of the coal were obtained. Then, (13) was implemented into the solid mechanics module of the COMSOL Multiphysics software as a viscoelastic constitutive equation. Combining the built-in plastic model of the solid mechanics module, the creep deformation under the same triaxial stress condition was simulated. The parameters used in the simulation are listed in Table 3, which are from the experimental results. The simulated results and the experimental data are plotted in Figure 8. The comparison shows that the creep model presented in this study can describe the coal sample's creep curve, which includes a transient creep stage, a decelerating creep stage, a steady creep stage, and an accelerating stage.

\subsubsection{Simulation of Gas Drainage Borehole Stability}

(1) Physical Model and Boundary Conditions. As shown in Figure 9, the physical model is $2 \mathrm{~m}$ in height and $2 \mathrm{~m}$ in width, and the diameter of the borehole is $0.1 \mathrm{~m}$. AB, BC, and $\mathrm{AD}$ have a constant normal stress boundary condition, $P_{0}=10 \mathrm{MPa}$. The $\mathrm{DC}$ is under a fixed boundary condition, $U_{x}=U_{y}=0$. The simulation was conducted under two kinds of stress boundary conditions of the borehole: (1) no active 
TABle 3: Parameters of the coal from Huangling no. 2 coal mine.

\begin{tabular}{lccccccc}
\hline Density $\left(\mathrm{g} / \mathrm{cm}^{3}\right)$ & $G_{\mathrm{M}}(\mathrm{GPa})$ & $G_{\mathrm{k}}(\mathrm{GPa})$ & $\eta_{\mathrm{M}}(\mathrm{MPa} \cdot \mathrm{h})$ & $\eta_{\mathrm{K}}(\mathrm{MPa} \cdot \mathrm{h})$ & $c(\mathrm{MPa})$ & $\psi\left(\left(^{\circ}\right)\right.$ & $\varphi\left(^{\circ}\right)$ \\
\hline 1.38 & 1.94 & 3.26 & 117.5 & 10.2 & 0.85 & 17 & 31.5 \\
\hline
\end{tabular}

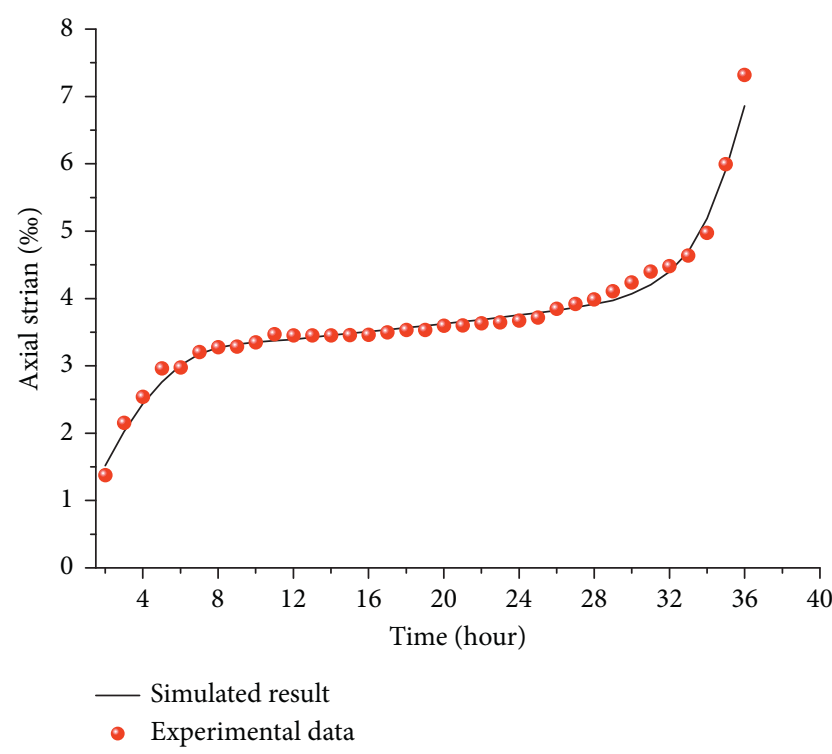

Figure 8: Comparison between experimental data and simulated results.

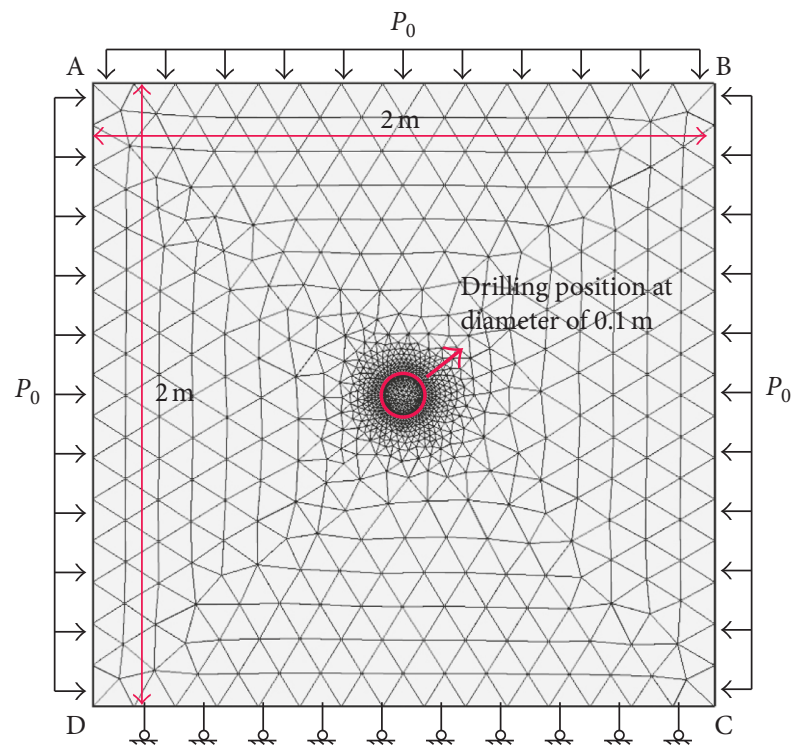

FIgure 9: Physical model and boundary conditions.

support imposed on the hole wall, and (2) an active support, $S_{1}$, imposed on the inner wall of the borehole, which is from the swelling of the DE material and can be assumed as presented in the following equation. The parameters in this simulation are chosen from Table 3.

$$
S_{1}=1.5 \cdot \frac{\exp ((T-40) / 20)}{1+\exp ((T-40) / 20)} \text {. }
$$

(2) Borehole Stability Analysis. The vertical stress distribution around a gas drainage borehole is illustrated in Figure 10. The vertical stress near the hole wall is lower than the in situ stress, which indicates damage to the coal that is close to the borehole after borehole excavation. This damage region extends over time. For the borehole sealed without active support, the maximum damage distance to the hole wall was $47 \mathrm{~mm}$ one day after drilling excavation. For 2 days and 5 days after borehole drilling, the maximum damage distance increased to $96 \mathrm{~mm}$ and $123 \mathrm{~mm}$, respectively. However, when the active support, $S_{1}$, was imposed on the hole wall, the maximum damage distances were reduced to $24 \mathrm{~mm}, 37 \mathrm{~mm}$, and $51 \mathrm{~mm}$ at the 1st day, 2nd day, and 5th day after drilling excavation.

Figure 11 illustrates the distribution of the plastic region around the borehole. The plastic region also extends over time but shrinks when the active support is imposed on the borehole wall. Without active support on the hole wall, the radii of the plastic regions were $129 \mathrm{~mm}, 220 \mathrm{~mm}$ and $246 \mathrm{~mm}$ for 1 day, 2 days, and 5 days after drilling, respectively. However, with active support, $S_{1}$, the radii of the plastic regions were reduced to $121 \mathrm{~mm}, 165 \mathrm{~mm}$, and $183 \mathrm{~mm}$ for 1 day, 2 days, and 5 days after drilling, respectively.

The stability of the borehole weakens over time due to the creep of the coal, which is consistent with the results of Liu and Paraschiv-Munteanu et al. [42, 43]. However, the active support imposed on the borehole can efficiently limit the enlargement of the damage region and the plastic region, resulting in improved stability of the gas drainage borehole. Therefore, the borehole sealed by the DE material is more stable than that sealed by materials lacking swelling pressure.

\section{Field Tests}

4.1. Field Situation. To compare the gas drainage borehole sealing effect for the DE material and a conventional material, field tests were carried out at panel 207 of Huangling no. 2 coal mine in China. The buried depth of the panel 207 is $369 \mathrm{~m}-$ $413 \mathrm{~m}$, and the dip angle ranges from $4^{\circ}$ to $7^{\circ}$. The gas pressure of the panel is $0.29 \mathrm{MPa}-1.51 \mathrm{MPa}$, and the gas content ranges from $6.75 \mathrm{~m}^{3} / \mathrm{t}$ to $14.52 \mathrm{~m}^{3} / \mathrm{t}$. The coal seam permeability in this panel is measured as $6.7 \times 10^{-17} \mathrm{~m}^{2} \sim 3.6 \times 10^{-16} \mathrm{~m}^{2}$, with a mean value of $2.5 \times 10^{-16} \mathrm{~m}^{2}$. The conventional sealing material used for the field test consisted of OPC, water reducer, and aluminum powder (mass ratio of $1: 0.006: 0.002$ ). This material has a free swelling ratio of $15 \%$ and a maximum swelling pressure of $50 \mathrm{kPa}$ under a water-solid ratio of $0.6: 1$. In this panel, forty coal seam boreholes were prepared and divided into two groups. The boreholes in Group 1 were sealed by the DE material, and the boreholes in Group 2 were sealed by the conventional sealing material. The sealing length of the gas drainage borehole in the panel 207 is $16 \mathrm{~m}$. After sealing, 


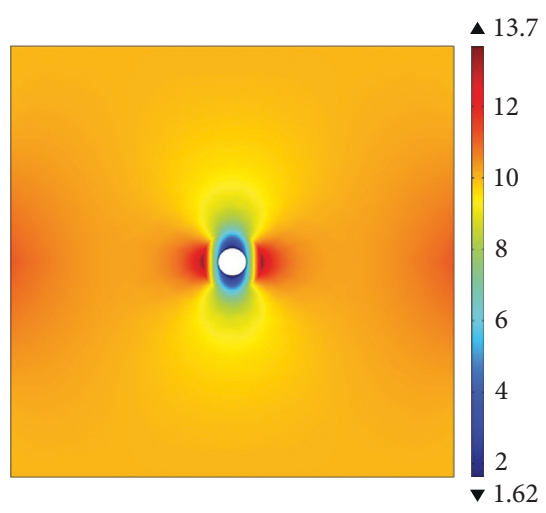

(a)

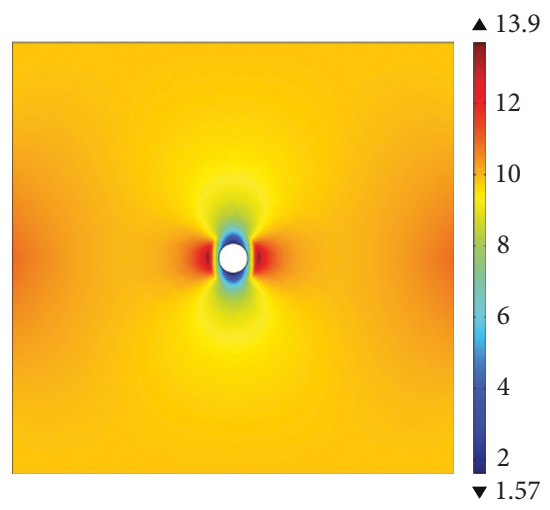

(d)

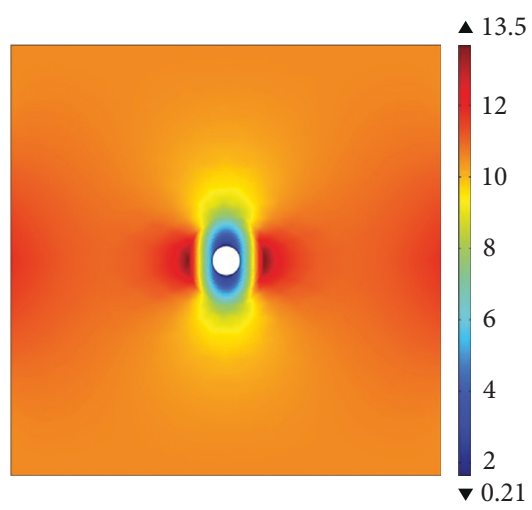

(b)

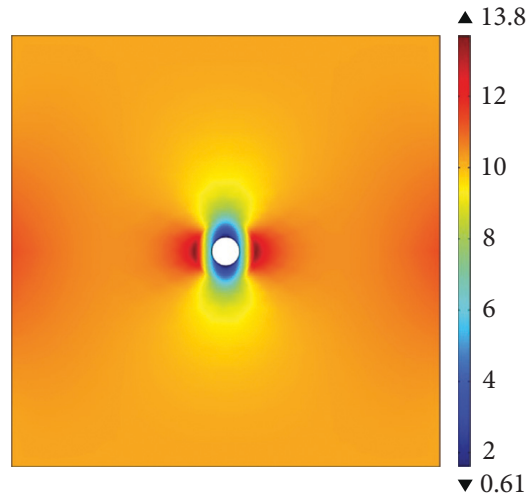

(e)

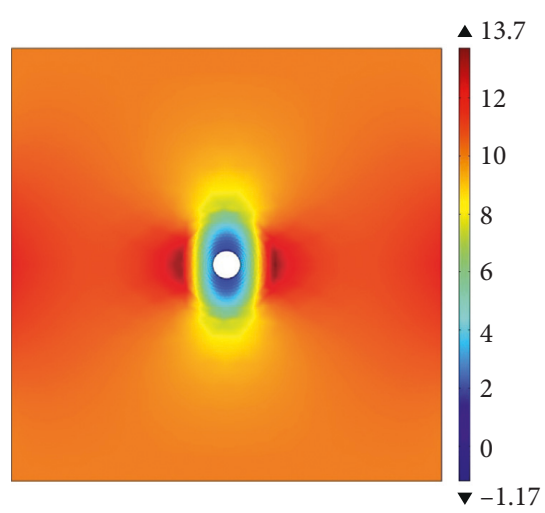

(c)

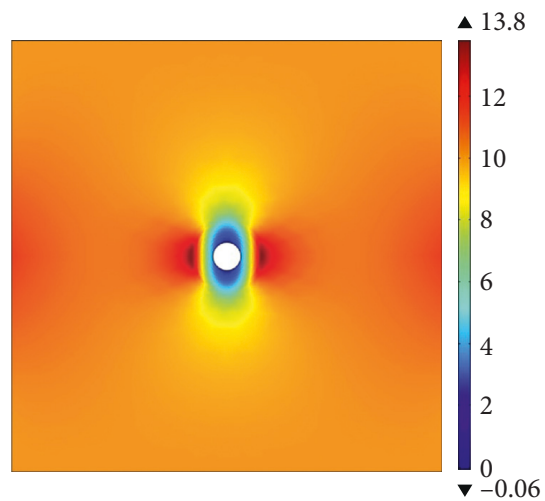

(f)

FIGURE 10: Distribution of vertical stress around borehole. (a) No active support, 1d. (b) No active support, 2d. (c) No active support, 5d. (d) Active support, $S_{1}-1 d$. (e) Active support, $S_{1}-2 d$. (f) Active support, $S_{1}-5 d$.

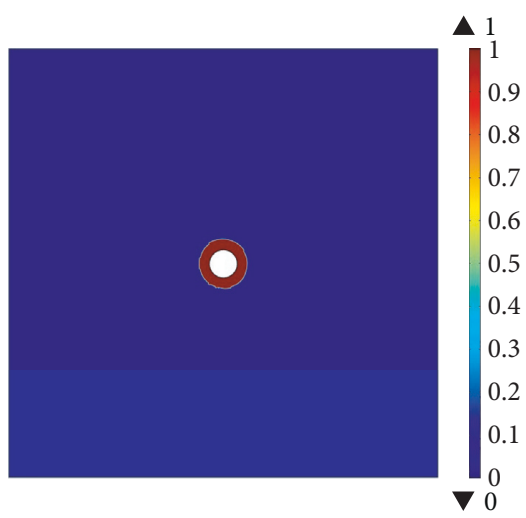

(a)

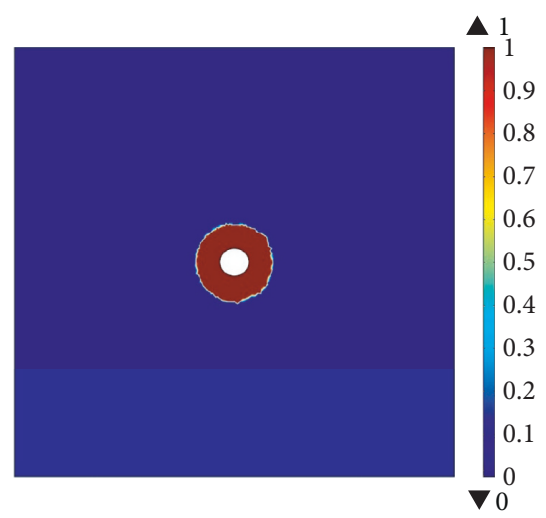

(b)

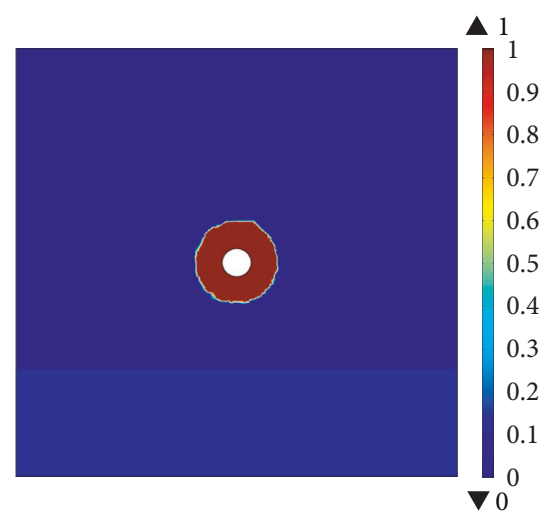

(c)

Figure 11: Continued. 


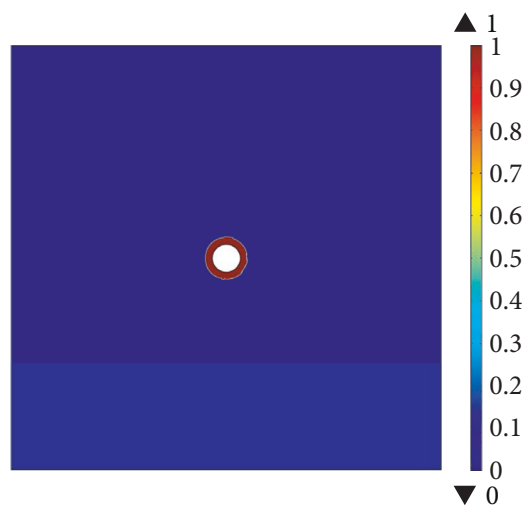

(d)

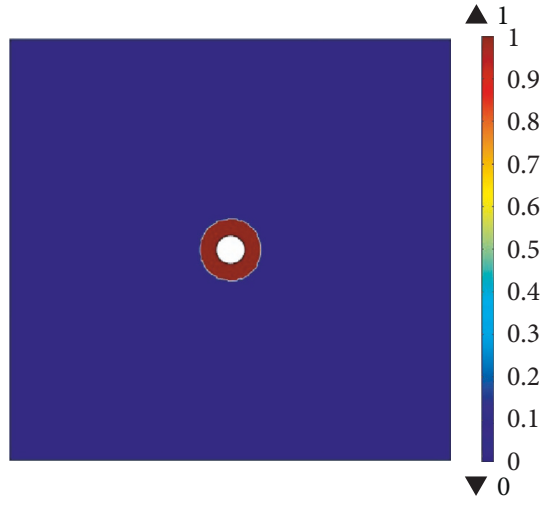

(e)

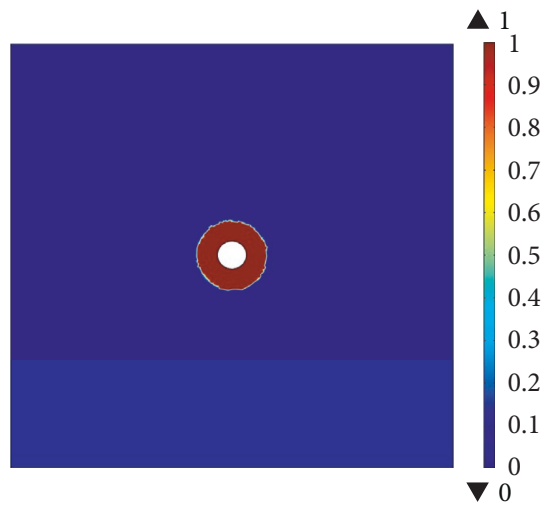

(f)

FIGURE 11: Distribution of the plastic region around the borehole. (a) No active support, 1d. (b) No active support, 2d. (c) No active support, 5d. (d) Active support, $S_{1}-1 d$. (e) Active support, $S_{1}-2 d$. (f) Active support, $S_{1}-5 d$.

the boreholes were connected to the drainage net with a negative drainage pressure of $-15 \mathrm{kPa}$.

4.2. Gas Drainage Performance Comparison. Figure 12 shows the gas concentrations recorded in the drainage process for 50 days. On the first day, the gas drainage concentrations were $48 \%$ and $47 \%$ in Group 1 and Group 2, respectively. Then, in Group 2, the gas concentration attenuated very fast, changing from $47 \%$ to $4 \%$ during 50 days. However, in Group 1, the gas concentration decreased slowly from $48 \%$ to $32 \%$. Throughout the whole drainage process, the average gas concentration of Group 1 was $39.1 \%$, more than twice the average concentration (17\%) of Group 1. Field tests results revealed no discernible difference between the sealing effect of the conventional sealing material and the DE material at the beginning stage. However, throughout the entire drainage process, the active support from the DE material significantly improved the gas drainage performance, compared with the borehole sealed using the conventional sealing material.

\section{Conclusions}

To improve coal seam gas drainage performance, we developed a DE material for borehole sealing. This material is composed of OPC, mineral powder, a solid expansion agent, bentonite, naphthalene water reducer and aluminum powder. The swelling process of the DE material includes an initial swelling stage affected by the foaming effect of the aluminum powder and a secondary swelling stage induced by the growth and formation of the crystals. According to the results, the key conclusions are summarized as follows:

(1) The swelling test device was used to test the swelling pressure of the DE material under four constraint conditions. The swelling pressure properties of the DE material revealed that (a) the swelling pressure of the DE material is time-dependent during its hydration, and the relationship described here of the swelling pressure and time can describe this timedependent behavior accurately and (b) the radial swelling potential is principally formed during the secondary swelling stage.

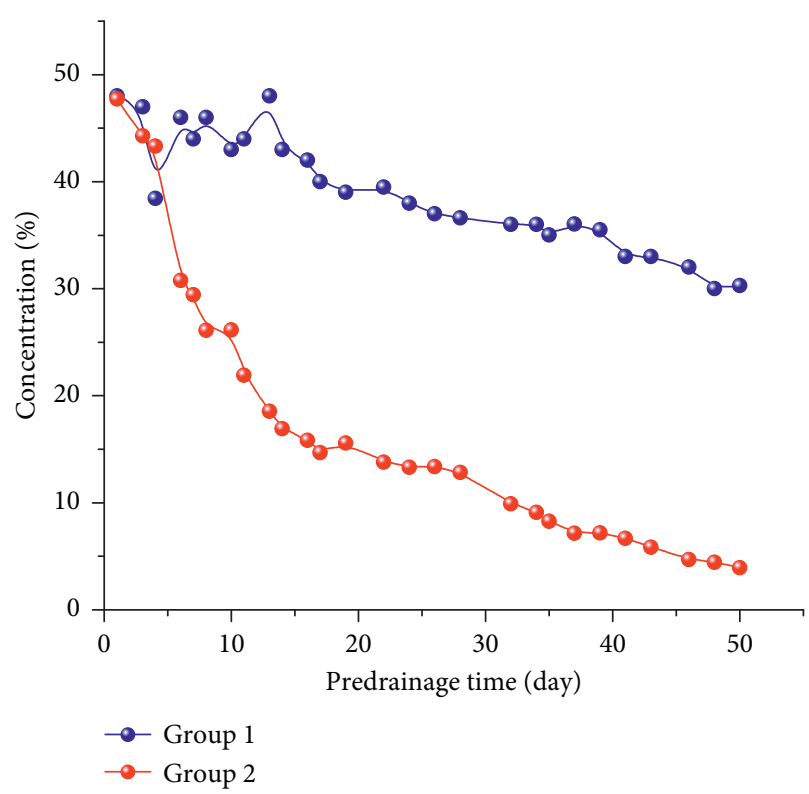

Figure 12: Gas drainage concentrations in the field test.

(2) The stability of a gas drainage borehole weakens over time due to the creep of the coal. However, the active support imposed on the hole wall can efficiently inhibit the enlargement of the damage region and the plastic region, for improved stability of the gas drainage borehole.

(3) Field tests results show significantly improved gas drainage performance of the borehole sealed by the DE material. The DE-sealed borehole had an average gas concentration in 50 days of $39.1 \%$, more than twice that of the borehole sealed by the conventional sealing material.

\section{Appendix}

\section{A. Derivation Process of (8)}

With the swelling of the DE material, the radial swelling pressure does work to the hollow cylinder. Part of the radial 
swelling potential is converted to elastic deformation energy and is saved in the cylinder, and this can be calculated by the integration method. As shown in Figure 13, the hollow cylinder can be divided into numerous unit hollow cylinders, whose thicknesses are all $d r$. The unit hollow cylinder is composed of numerous rectangular units, with length of $r \cdot d \varphi$ and width of $d r$. Therefore, the elastic deformation energy stored in the hollow cylinder and the RSPI can be expressed as

$$
\mathrm{RSPI}=W_{\mathrm{H}}=\int_{r_{0}}^{r_{0}+\delta} \int_{0}^{2 \pi} W_{\mathrm{R}},
$$

where $W_{\mathrm{R}}$ represents the elastic deformation energy saved in a rectangular unit.

Based on the elastic theory, the stresses and strains in the rectangular unit can be expressed as

$$
\begin{aligned}
& P_{r-1}=-P_{r-1}=P_{r} \cdot \frac{r_{0}^{2}}{r^{2}}, \\
& \varepsilon_{r-1}=-\varepsilon_{r-2}=-d t,
\end{aligned}
$$

where $P_{r-1}$ and $P_{r-2}$ are the normal and tangential principal stresses, respectively, and $\varepsilon_{r-1}$ and $\varepsilon_{r-2}$ are the normal and tangential principal strains. It should be noted that the stress and strain along the axis of the cylinder are both 0 . Therefore, the elastic deformation energy saved in the rectangular unit can be calculated as follows:

$$
\begin{aligned}
W_{\mathrm{R}} & =W_{\mathrm{R} 1}+W_{\mathrm{R} 2}, \\
W_{\mathrm{R} 1} & =\frac{1}{2} L_{0} P_{r-1} \varepsilon_{r-1} r d \varphi d r, \\
W_{\mathrm{R} 2} & =\frac{1}{2} L_{0} P_{r-2} \varepsilon_{r-2} r d \varphi d r,
\end{aligned}
$$

where $W_{\mathrm{R} 1}$ and $W_{\mathrm{R} 2}$ represent the normal and tangential elastic deformation energies, respectively.

Incorporating (A.2) into (A.3), we can obtain

$$
W_{\mathrm{R}}=P_{r} L_{0} r_{0}^{2} \frac{d t}{r} d r d \varphi
$$

where $L_{0}$ is the length of the hollow cylinder and is equal to $100 \mathrm{~mm}$.

Then, combining with (3), (A.4) can be rewritten as

$$
\begin{aligned}
W_{\mathrm{R}} & =A\left(B+\frac{C}{r^{2}}\right) \frac{d \varphi d r}{r}, \\
A & =\frac{P_{r}^{2} r_{0}^{3} L_{0}(1+\mu)}{2 \delta E}, \\
B & =1-2 \mu, \\
C & =\left(r_{0}+\delta\right)^{2} .
\end{aligned}
$$

Finally, incorporating (A.5) into (A.1), we can obtain

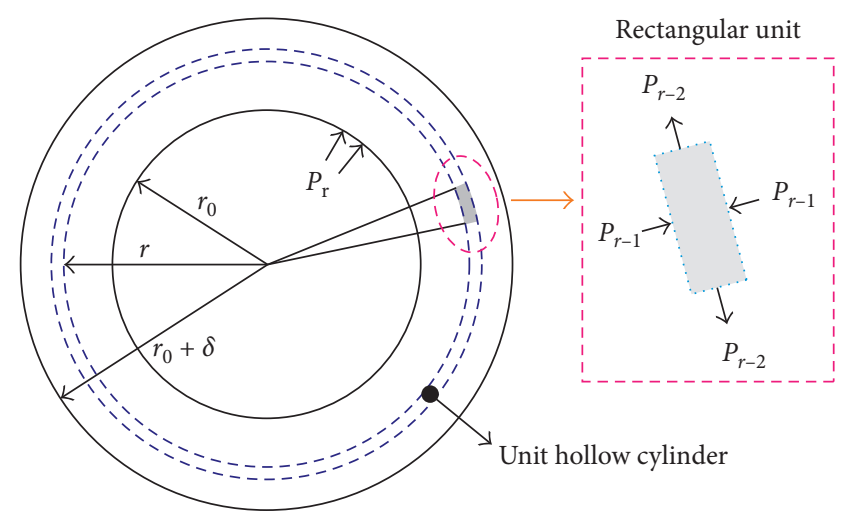

FIgURE 13: Unit division of the hollow cylinder.

$$
\begin{aligned}
W_{\mathrm{H}} & =\mathrm{RSPI}=\int_{r_{0}}^{r_{0}+\delta} \int_{0}^{2 \pi} \frac{A}{r}\left(B+\frac{C}{r^{2}}\right) d \varphi d r, \\
A & =\frac{P_{r}^{2} r_{0}^{3} L_{0}(1+\mu)}{2 \delta E}, \\
B & =1-2 \mu, \\
C & =\left(r_{0}+\delta\right)^{2} .
\end{aligned}
$$

\section{Data Availability}

No data were used to support this study.

\section{Conflicts of Interest}

The authors declare that there are no conflicts of interest regarding the publication of this paper.

\section{Acknowledgments}

This work was supported by the Henan Province Science and Technology Innovation Talent Program (no. 164200510002).

\section{Supplementary Materials}

A dataset is provided as supplementary materials, which includes the experimental results of free swelling ratio, EDS data, and swelling pressure of the DE material and the values of RSPI calculated. (Supplementary Materials)

\section{References}

[1] Z. J. Pan and D. A. Wood, "Coal bed methane (CBM) exploration, reservoir characterisation, production, and modelling: a collection of published research (2009-2015)," Journal of Natural Gas Science and Engineering, vol. 26, no. 1, pp. 1472-1484, 2015.

[2] K. Baris, C. Keles, N. Ripepi et al., "The first commercial coal bed methane project in Turkey-Reservoir simulation and prefeasibility study for the Amasra coalfield," International Journal of Oil Gas and Coal Technology, vol. 13, no. 2, pp. 170-199, 2016. 
[3] N. Ripepi, K. Louk, J. Amante, C. Schlosser, X. Tang, and E. Gilliland, "Determining coalbed methane production and composition from individual stacked coal seams in a multizone completed gas well," Energies, vol. 10, no. 10, p. 1533, 2017.

[4] J. Hansen and A. Lacis, "Sun and dust versus greenhouse gases: an assessment of their relative roles in global climate change," Nature, vol. 346, no. 6286, pp. 713-719, 1990.

[5] K. Warmuzinski, "Harnessing methane emissions from coal mining," Process Safety and Environmental Protection, vol. 86, no. 5, pp. 315-320, 2008.

[6] T. Xia, F. Zhou, J. Liu, and F. Gao, "Evaluation of the predrained coal seam gas quality,” Fuel, vol. 130, pp. 296-305, 2014.

[7] Y. Gao, B. Q. Lin, W. Yang et al., "Drilling large diameter cross-measure boreholes to improve gas drainage in highly gassy soft coal seams," Journal of Natural Gas Science and Engineering, vol. 26, pp. 193-204, 2015.

[8] J. Jiang, Y. Cheng, P. Zhang et al., "CBM drainage engineering challenges and the technology of mining protective coal seam in the Dalong Mine, Tiefa Basin, China," Journal of Natural Gas Science and Engineering, vol. 24, pp. 412-424, 2015.

[9] Y. Chen, J. Xu, S. Peng, F. Yan, and C. Fan, "A gas-solidliquid coupling model of coal seams and the optimization of gas drainage boreholes," Energies, vol. 11, no. 3, p. 560, 2018.

[10] T. Q. Xia, F. B. Zhou, J. S. Liu, S. Y. Hu, and Y. K. Liu, “A fully coupled coal deformation and compositional flow model for the control of the pre-mining coal seam gas extraction," International Journal of Rock Mechanics and Mining Sciences, vol. 72, pp. 138-148, 2014.

[11] X. W. Xiang, C. Zhai, Y. Xu, and J. Z. Xu, "A flexible gel sealing material and a novel active sealing method for coalbed methane drainage boreholes," Journal of Natural Gas Science and Engineering, vol. 26, pp. 1187-1199, 2015.

[12] C. Zheng, M. S. Kizil, Z. Chen, and S. M. Aminossadati, "Effects of coal properties on ventilation air leakage into methane gas drainage boreholes: application of the orthogonal design," Journal of Natural Gas Science and Engineering, vol. 45, pp. 88-95, 2017.

[13] H. Farzaneh, M. Fahimi, and Y. Saboohi, "Optimal power generation from low concentration coal bed methane in Iran," Energy Sources, Part A: Recovery, Utilization, and Environmental Effects, vol. 38, no. 4, pp. 590-596, 2016.

[14] F. B. Zhou, J. Li, X. Ze et al., "A study of the second hole sealing method to improve gas drainage in coal seams," Journal of China University of Mining and Technology, vol. 38, no. 6, pp. 764-768, 2009.

[15] F. B. Zhou, Y. N. Sun, H. J. Li, and G. Yu, "Research on the theoretical model and engineering technology of the coal seam gas drainage hole sealing," Journal of China University of Mining and Technology, vol. 45, no. 3, pp. 433-439, 2016.

[16] C. Zhai, X. W. Xiang, Q. L. Zou, X. Yu, and Y. Xu, "Influence factors analysis of a flexible gel sealing material for coal-bed methane drainage boreholes," Environmental Earth Sciences, vol. 75, no. 5, pp. 1-13, 2016.

[17] Q. Q. Liu, Y. P. Cheng, L. Yuan et al., "A new effective method and new materials for high sealing performance of crossmeasure CMM drainage boreholes," Journal of Natural Gas Science and Engineering, vol. 21, pp. 805-813, 2014.

[18] Z. F. Wang, Y. Zhou, Y. N. Sun, and Y. L. Wang, "Novel gas extraction borehole grouting sealing method and sealing mechanism," Journal of China Coal Society, vol. 40, no. 3, pp. 588-595, 2015.
[19] F. Shuai, Simulation of swelling pressure measurements on expansive soils, Ph.D. dissertation, University of Saskatchewan, Saskatchewan, Canada, 1996.

[20] L. Liu, "Prediction of swelling pressures of different types of bentonite in dilute solutions," Colloids and Surfaces A: Physicochemical and Engineering Aspects, vol. 434, no. 19, pp. 303-318, 2013.

[21] C. Butscher, S. Scheidler, H. Farhadian, H. Dresmann, and P. Huggenberger, "Swelling potential of clay-sulfate rocks in tunneling in complex geological settings and impact of hydraulic measures assessed by 3D groundwater modeling," Engineering Geology, vol. 221, pp. 143-153, 2017.

[22] R. Bag and A. Rabbani, "Effect of temperature on swelling pressure and compressibility characteristics of soil," Applied Clay Science, vol. 136, pp. 1-7, 2017.

[23] G. Montesh, "Swelling-shrinkage measurements of bentonite using coupled environmental scanning electron microscopy and digital image analysis," Journal of Colloid and Interface Science, vol. 284, no. 1, pp. 271-277, 2005.

[24] M. Bradbury and B. Baeyens, "Experimental and modelling studies on the $\mathrm{pH}$ buffering of MX-80 bentonite porewater," Applied Geochemistry, vol. 24, no. 3, pp. 419-425, 2009.

[25] E. Tazawa, S. Miyazawa, and T. Kasai, "Chemical shrinkage and autogenous shrinkage of hydrating cement paste," Cement and Concrete Research, vol. 25, no. 2, pp. 288-292, 1995.

[26] N. Nasir, R. Jumaidin, H. Efendy et al., "Preparation of macroporous ceramic materials by using aluminium powder as foaming agent," Applied Mechanics and Materials, vol. 699, pp. 336-341, 2014.

[27] X. Gao, "Elasto-plastic analysis of an internally pressurized thick-walled cylinder using a strain gradient plasticity theory," International Journal of Solids and Structures, vol. 40, no. 23, pp. 6445-6455, 2003.

[28] H. Shi, G. Chen, Y. Xiao, W. Yu, and Y. Yuan, "Mineral additives and expansion behaviors of hardened cement paste," Journal of Building Materials, vol. 2, no. 4, pp. 344-348, 1999.

[29] H. Shi, G. Chen, and W. Yu, "Expansion behavior and stress match of hardened cement pastes," Journal of Tongji University, vol. 25, no. 6, pp. 690-694, 1997.

[30] D. Dermatas, "Ettringite-induced swelling in soils: state-ofthe-art," Applied Mechanics Reviews, vol. 48, no. 10, pp. 659-675, 1995.

[31] D. H. Moon, D. Dermatas, M. Wazne, A. M. Sanchez, M. Chrysochoou, and D. G. Grubb, "Swelling related to ettringite crystal formation in chromite ore processing residue," Environmental Geochemistry and Health, vol. 29, no. 4, pp. 289-294, 2007.

[32] H. F. W. Taylor, C. Famy, and K. L. Scrivener, "Delayed ettringite formation," Cement and Concrete Research, vol. 31, no. 5, pp. 683-693, 2001.

[33] D. Damidot, M. Atkins, and F. P. Glasser, "Phase development in cement in relation to the secondary ettringite problem," Advances in Cement Research, vol. 7, no. 26, pp. 57-68, 1995.

[34] I. Odler and J. C. Subauste, "Investigations on cement expansion associated with ettringite formation," Cement and Concrete Research, vol. 29, no. 5, pp. 731-735, 1999.

[35] P. Yan, F. Zheng, J. Peng, and X. Qin, "Relationship between delayed ettringite formation and delayed expansion in massive shrinkage-compensating concrete," Cement and Concrete Composites, vol. 26, no. 6, pp. 687-693, 2004.

[36] P. Akpinar and I. Casanova, "A combined study of expansive and tensile strength evolution of mortars under sulfate attack: implications on durability assessment," Materiales De Construccion, vol. 60, no. 297, pp. 59-68, 2010. 
[37] A. Pavoine, L. Divet, and S. Fenouillet, "A concrete performance test for delayed ettringite formation: part II validation," Cement and Concrete Research, vol. 36, no. 12, pp. 2144-2151, 2006.

[38] A. Ramon, Expansion mechanisms in sulphated rocks and soils, Ph.D dissertation, Universitat Politècnica de Catalunya, Barcelona, Spain, 2014.

[39] R. Chen and Z. Chen, "Study on the hydration kinetics of free $\mathrm{CaO}$ in high calcium fly ash," Journal of Building Materials, vol. 2, pp. 147-150, 2000.

[40] J. Kang, F. Zhou, C. Liu, and Y. Liu, "A fractional nonlinear creep model for coal considering damage effect and experimental validation," International Journal of Non-Linear Mechanics, vol. 76, pp. 20-28, 2015.

[41] S. Yang, P. Xu, and P. Ranjith, "Evaluation of creep mechanical behavior of deep-buried marble under triaxial cyclic loading," Arabian Journal of Geosciences, vol. 8, no. 9, pp. 6567-6582, 2015.

[42] C. Liu, F. Zhou, and J. Kang, "Application of a non-linear viscoelastic-plastic rheological model of soft coal on borehole stability," Journal of Natural Gas Science and Engineering, vol. 36, pp. 1303-1311, 2016.

[43] I. Paraschiv-Munteanu and N. D. Cristescu, "Stress relaxation during creep of rocks around deep boreholes," International Journal of Engineering Science, vol. 39, no. 7, pp. 737-754, 2001. 


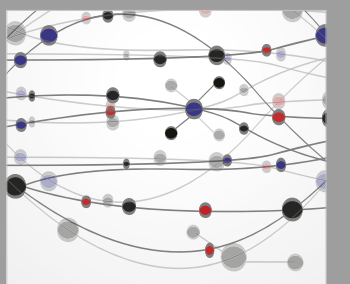

The Scientific World Journal
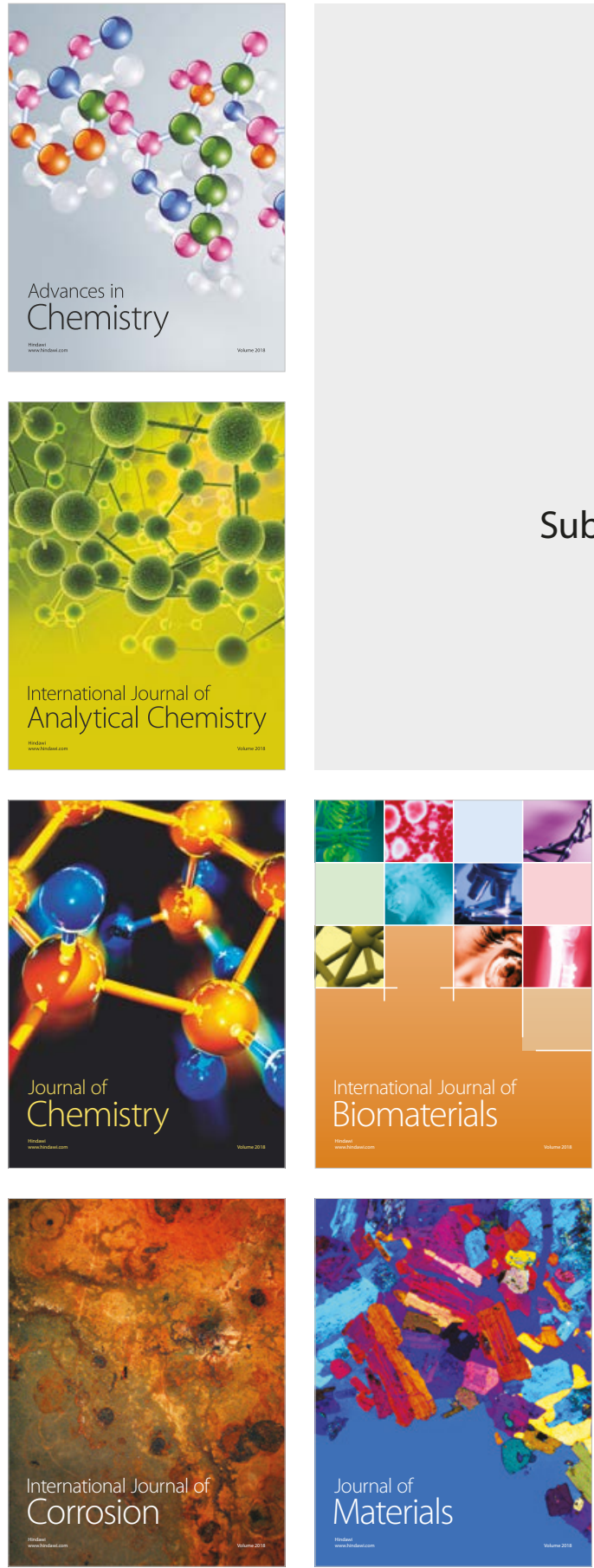

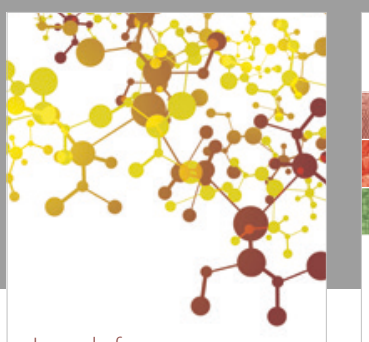

Journal of

Applied Chemistry
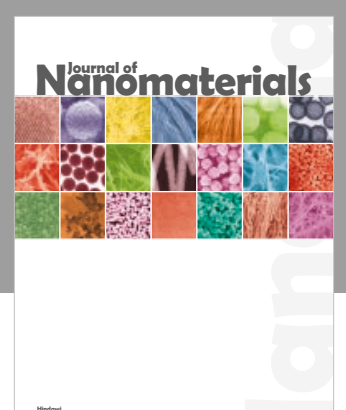

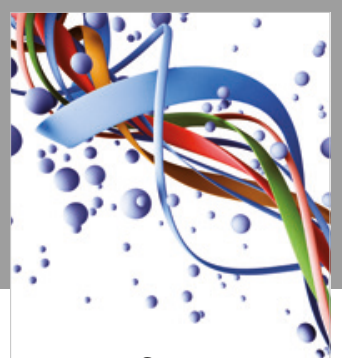

Scientifica

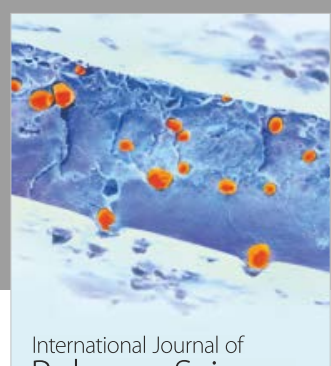

Polymer Science

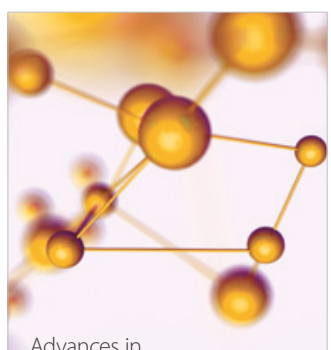

Physical Chemistry
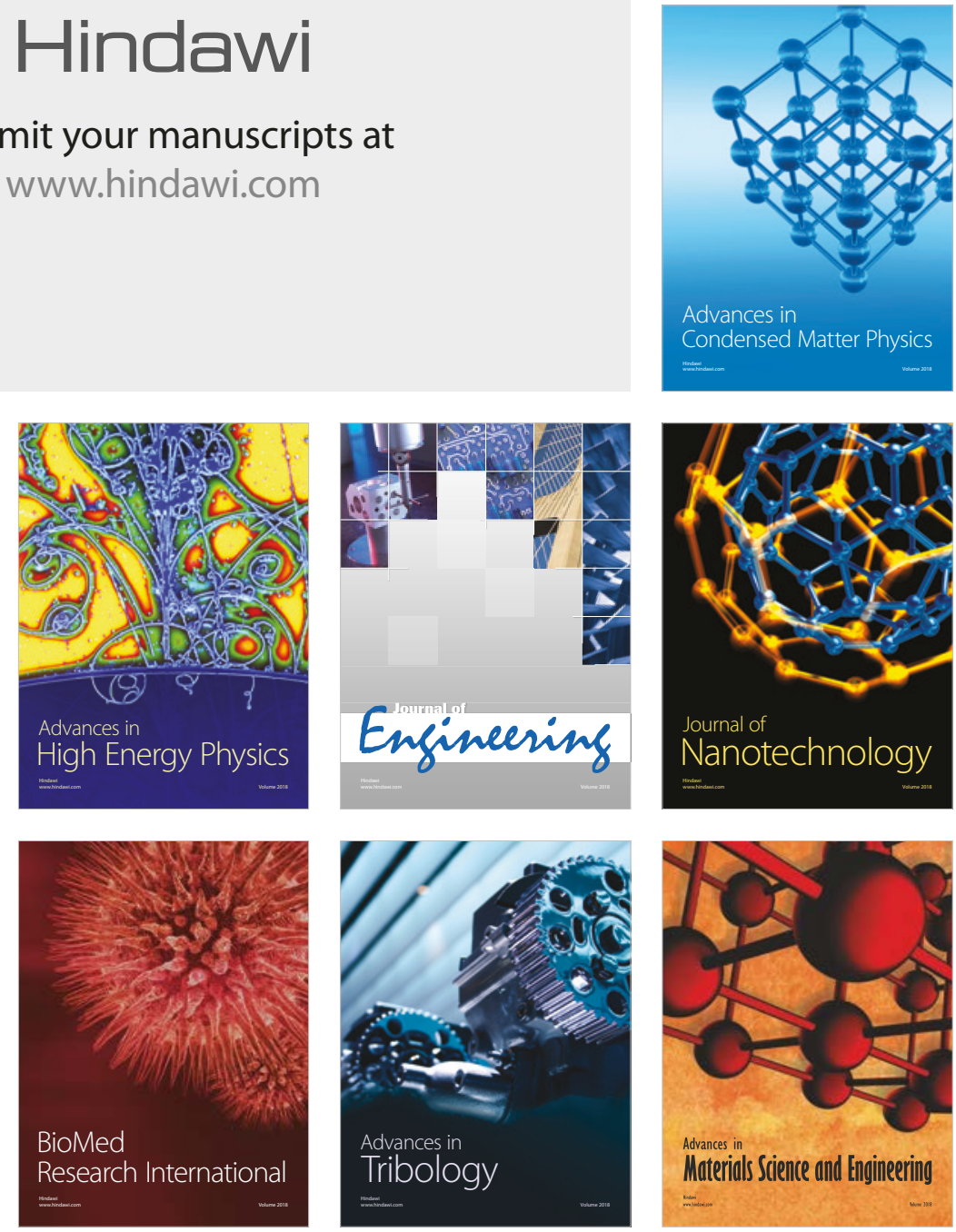